\title{
PREVALENCE OF HUMAN MALARIA; IT'S CORRELATION WITH THROMBOCYTOPENIA AND TREATMENT IN PATIENTS OF DISTRICT RAHIM YAR KHAN.
}

\section{Dr. Muhammad Zafar Majeed ${ }^{1}$, Dr. Muhammad Shahbaz Hussain ${ }^{2}$, Faiza Sarwar ${ }^{3}$}

1. MBBS, FCPS (Med) Associate Professor of Medicine Sheikh Zayed Medical College/Hospital Rahim Yar Khan. 2. MBBS, M. Phil

Assistant Professor Microbiology Sheikh Zayed Medical

College/Hospital Rahim Yar Khan.

3. Medical Technologist

Sheikh Zayed Medical

College/Hospital Rahim Yar Khan.

Correspondence Address:

Dr. Muhammad Shahbaz Hussain MBBS, M. Phil

Assistant Professor Microbiology Sheikh Zayed Medical

College/Hospital Rahim Yar Khan

drmshahbaz@yahoo.com

Article received on: 20/01/2016

Accepted for publication: 30/04/2016

Received after proof reading: $26 / 05 / 2016$

\begin{abstract}
Malaria is one of the devastating diseases worldwide. More than 3 billion people live under the threat of malaria in endemic countries and kills more than one million each year. Malaria leads to multiple hematological (thrombocytopenia) and other abnormalities like renal system, nervous system with increased morbidity and mortality. Aim: The present study was conducted to determine the prevalence of human malaria, its correlation with thrombocytopenia and treatment in patients of District Rahim Yar Khan. Materials and Methods: A total of 200 patients including 140 males and 60 females were the part of our study. Blood samples collection was done during September to November following monsoon season. Patients were diagnosed through peripheral blood smear. Both P. falciparum and P. vivax parasites against 300 white blood cells (WBCs) were examined on the thick smear. Platelet count was done by using an automated cell count analyzer. A platelet count of less than $150 \times 10 \% / \mathrm{L}$ defined thrombocytopaenia. First line of treatment was Chloroquine in cases of Plasmodium vivax whereas Neo fansidar in cases of Plasmodium falciparum. Results: Gender wise distribution of patients was $140(70 \%)$ males and $60(30 \%)$ females. We had $74(37 \%)$ patients from urban and $126(63 \%)$ from rural population. Malaria was most frequent $64 \%$ by P.vivax and $36 \%$ by P.falciparum. Fever was high during admission to hospital and after usage of antimalarials recovery and improvement in number of platelets was noted. Conclusion: The high prevalence rate of P. vivax pose a major health hazard but of $P$. falciparum also may lead to serious complications. The high frequency of human malaria infection should be a major concern for authorities in the fight against malaria control programs in Pakistan.
\end{abstract}

Key words: Malaria, Plasmodium vivax, Plasmodium falciparum, Thrombocytopenia

Article Citation: Majeed MZ, Hussain MS, Sarwar F. Prevalence of human malaria; it's correlation with thrombocytopenia and treatment in patients of district Rahim Yar Khan. Professional Med J 2016;23(6):655-659. DOI: 10.17957/ TPMJ/16.3277

INTRODUCTION

Malaria is a disease of increased morbidity and mortality caused by protozoan parasite of the genus plasmodium which is transmitted to humans by infected female anopheles mosquitoes. ${ }^{1}$

Severe malaria is worldwide that affects health and wealth of the nation and individuals. It is understood that malaria is a disease of poverty and a reason of poverty. ${ }^{2}$

Malaria is widespread in tropical and subtropical areas across the equator in the world, including many parts of Sub-Saharan Africa, Americas and Asia. ${ }^{3}$ Signs and symptoms of malaria usually begin 8-25 days after infection, but symptoms may appear later in those who had taken anti-malarial drugs and prevention. The first manifestations of malaria resembles flu-like symptoms and can be like gastroenteritis, septicemia and viral diseases. The sufferer of the disease presents with, fever, headache, vomiting, shivering, hemolytic anemia, jaundice, joint pain, hemoglobinuria, convulsions and retinal damage..$^{4,5,6,7}$ Malaria is the main health risk in Pakistan and severity of the cases can lead to coma and eventually death. There is a plenty of stagnant water after heavy rains in the country, which provides an ideal mosquito breeding environment. In Pakistan, malaria frequently spreads during July to November. ${ }^{8}$

Five major plasmodium species i.e. P. Knowlesi, P. Malariae, P. Ovale, P. Falciparum and P. Vivax, are major contributors of malaria in humans. ${ }^{9}$ Two 
species of Plasmodium are the most common in Pakistan, P. vivax (74\%) and most deadly P. falciparum (26\%). ${ }^{10}$ Benign tertian malaria caused by Plasmodium vivax is a tropical disease distributed globally. Benign tertian malaria has now lost its notoriety, mainly due to the extensive availability of the strong and effective drugs against malaria. ${ }^{11}$

Megakaryocytes is the main source of platelet origination from bone marrow. The normal range of platelets is $1,50,000-4,00,000 / \mathrm{cmm}$. Platelet count in thrombocytopenia is below $1,50,000$ / $\mathrm{cmm}$.Various haematological abnormalities have been reported in malaria, thrombocytopaenia is common among them. Thrombocytopenia is attributed to accumulation of platelets and a shorter life span of platelets in malaria. Thrombocytopenia associated with elevated serum concentrations of anti-inflammatory cytokines. ${ }^{12}$

Patients presenting with malaria dueto P.falciparum have variety of complications associated with high death rates due to Multi Organ Failure. ${ }^{13}$ However, $P$. vivax malaria leading to multi organ failure is well reported with changing trends. The profound low platelet count $5000 / \mathrm{cmm}$ in P. Vivax infection has been also documented. ${ }^{14}$

Approximately 243 million malarial cases reported every year. Nearly $8,63,000$ deaths were caused by malaria in 2008 according to recent report. In the Eastern Mediterranean Region (EMR) confirmed malaria cases are 5.7 million, of which $17 \%$ cases in Pakistan were recorded. The suspected cases of malaria from Pakistan in 2010 were 3,00000 due to flooding. For centuries the people are fighting against the parasites. In 2006 a study from Mansehra revealed 160 cases of malaria of which 12 cases suffering from $P$. falciparum 142 cases suffering from $P$. vivax. ${ }^{15}$ At Ayub Teaching Hospital Abbottabad 1994 patients were screened for malaria out of which 145 (7.2\%) were found infected, with 72.4\% P. vivax and $24.1 \%$ P. falciparum malaria. ${ }^{16} \mathrm{An}$ epidemiological study was carried in Quetta city reported $36 \%$ cases of cereberal malaria in adults
$64 \%$ cases in children. ${ }^{17}$ The incidence of malaria in patients with different age groups of rural and urban areas of Quetta showed P. falciparum infection (16.3\%, 17.7\%) in 2003 and 2004 respectively. ${ }^{18}$ The present study is designed to assess the prevalence of malarial parasites and its relationship with platelet deficiency in the population of district Rahim Yar Khan.

\section{MATERIALS AND METHODS}

The district of Rahim Yar Khan had registered a lot of malaria cases in the recent years repeatedly. Due to this reason present study was designed. The transmission of malaria affects Pakistan throughout the year, but usually, most of the cases reported in the period between September and November, after the monsoon season. A total of 200 patients including 140 males and 60 females were the part of our study. Patient's agreement was done before the sampling process. Detailed history from parents and patients especially malaria specific symptoms such as fever, chills and rigors, cough, diarrhea, headache, convulsions and generalized body aches was noted on especially designed Performa.

After the patient's history and clinical examination completion, three consecutive blood samples were collected in an ethylene diamine tetra acetic acid [EDTA] tube. Patients with positive results were integrated in this study. Thick and thin smears were made from blood samples. The thin smear was stained by Leishman's stain and thick smear by Giemsa's stain. The slide was then examined through microscope under oil immersion lens (100x). The parasites were counted on thick smear by quantifying maturation stages of both P. vivax and P. falciparum parasites separately against 300 WBC,s (leukocytes). Classification of the patients was done according to parasite density as mild, moderate, high and very high. An automated cell count analyzer (Sysmex) was used to perform CBC. A platelet count of less than $150 \times 10^{9} / \mathrm{L}$ was familiar with thrombocytopaenia. First line of treatment was Chloroquine in cases with P. vivax while $\mathrm{Neo}$ fansidar in cases with P.falciparum. Response to treatment was also noted carefully. Data was 
enter in Excel spreadsheet and analyzed to find statistically significant differences.

\section{RESULTS}

A total of 200 patients admitted to tertiary care hospital, Sheikh Zayed Medical College/Hospital Rahim yar Khan for the diagnosis and treatment of malaria were included in this study. Patients were from different age groups ranging from 1020 yrs (6\%), 21-30 yrs (30\%), 31-40 yrs (39\%), 4150 yrs (20\%), 51-60 yrs (5\%).

Gender wise distribution of patients was 140 (70\%) males and 60(30\%) females.

We had 74 (37\%) patients from urban and 126 (63\%) from rural population.

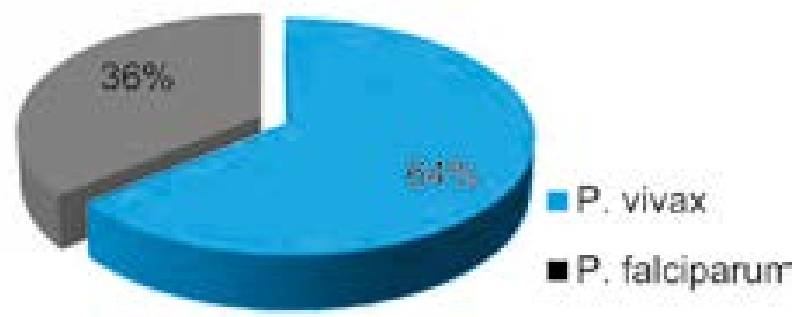

Figure-1. Frequency of Malarial species

\begin{tabular}{|l|c|c|}
\hline Number of days & Frequency & Percent (\%) \\
\hline Less than 3 days & 130 & $65 \%$ \\
\hline 3-7 days & 70 & $35 \%$ \\
\hline Total & 200 & 100.0 \\
\hline
\end{tabular}

Table-I. Duration of fever in days

\begin{tabular}{|l|c|c|}
\hline \multicolumn{1}{|c|}{ Platelet count } & Frequency & Percent (\%) \\
\hline Normal $(>150000)$ & 30 & 15.0 \\
\hline Mild $(50000-150000)$ & 154 & 77.0 \\
\hline Moderate $(20000-50000)$ & 12 & 6.0 \\
\hline Severe $(<20000)$ & 4 & 2.0 \\
\hline Total & 200 & 100.0 \\
\hline
\end{tabular}

\begin{tabular}{|l|c|c|}
\hline \multicolumn{1}{|c|}{ Platelet count } & Frequency & Percent (\%) \\
\hline Normal (>150000) & 30 & 15.0 \\
\hline Mild (50000-150000) & 154 & 77.0 \\
\hline Moderate (20000-50000) & 12 & 6.0 \\
\hline Severe (<20000) & 4 & 2.0 \\
\hline
\end{tabular}

Table-II. Distribution of platelet count with severity of malaria.

\begin{tabular}{|l|c|c|}
\hline \multicolumn{1}{|c|}{ Antimalarials } & Frequency & Percent (\%) \\
\hline Chloroquine & 118 & 59.0 \\
\hline Neo Fansidar & 82 & 41.0 \\
\hline Total & 200 & 100.0 \\
\hline \multicolumn{2}{|c|}{ Table-III. Recovery (\%) with antimalarials. } \\
\hline
\end{tabular}

\begin{tabular}{|l|c|c|}
\hline \multicolumn{1}{|c|}{ Days } & Frequency & Percent (\%) \\
\hline $1-3$ & 56 & 28 \\
\hline $4-6$ & 100 & 50 \\
7 and above & 44 & 22 \\
\hline Total & 200 & 100.0 \\
\hline \multicolumn{2}{|l|}{ Table-IV. Platelet recovery in days. } \\
\hline
\end{tabular}

\section{DISCUSSION}

In this study $70 \%$ males and $30 \%$ female patients were monitored. Males were affected mostly, due to the reasons males being more active and are exposed from sunrise to sunset. A study on malaria in North West Frontier Province (NWFP) reported P. falciparum malaria to be more widespread in male category and most vulnerable group was women. ${ }^{19}$ In our study P. vivax was most common (64\%) as compared to P. falciparum (36\%). Increased frequency of Plasmodium vivax malaria was recorded in other parts of the country i.e Okara (98\%), 90.4\% in Muzaffaabad, Multan $(60.5 \%)$ and $12.39 \%$ in south Punjab. Elevated rates of Plasmodium. vivax was also observed in Ziarat and Kohlu (88.5\% and 58.9\%), ACD and PCD (64.7\% and 54.6\%) in Ziarat.

A survey in Mozambique reported Plasmodium vivax $74 \%$ and most fatal Plasmodium. Falciparum $26 \%$ which is very close to our findings. ${ }^{20} \mathrm{~A}$ total of 200 malarial cases were monitored in Pakistan armed forces institute and found high frequency of $P$. vivax $(62.5 \%)$ infection compared with $P$. falciparum (36\%) infection. ${ }^{21}$ Data on malaria from Karachi and Sindh revealed Plasmodium. vivax infection to be two times greater than Plasmodium faciparum infection. ${ }^{22}$

Among the various haematological changes, thrombocytopaenia is most common in malaria especially in endemic countries. Fever in case of low platelet count is often an marker of malaria. Variation in platelet count from normal 150,000 
to severe as low as $20000 / \mathrm{cmm}$ were seen in our study. Incidence of thrombocytopenia was common in Plasmodium vivax infection in our study and is compare able to reported literature.

Present study confirmed that thrombocytopenia is more prevalent in Plasmodium vivax than Plasmodium falciparum. Important contributing factors resulting in low plateletcountare destructive sequestration of the platelets with coagulation disturbances, bone marrow depression, oxidative stress and splenomegaly. ${ }^{23}$ A study carried out on children from Karachi have reported low platelet counts in $72 \%$ of their patients, who were suffering from P. vivax infection. The duration of fever was also an important finding of our study. The fever in malaria was frequent in beginning 03 days of infection i.e. 65\% and less frequent in 3-7 days. Patient's recovery after completion of treatment with Neo Fansidar and Chloroquine was also recorded. Thrombocytopenia reverts to normal $59 \%$ was observed with Neo Fansidar and $41 \%$ with chloroquine.

\section{CONCLUSION}

The high prevalence (81\%) of P. vivax showing a substantial health risk in the district of Rahim Yar Khan. 70 to 136 districts of Pakistan (99 million population) and more than13.8 million people due to the recent floods in Pakistan have been affected and District Rahim Yar Khan of Punjab Province is one of the area most affected. The abundance of mosquito vectors in the presence of highly vulnerable populations commonly increases the frequency of overall rate of Malaria in relation to low platelet count. Patients recovered with antimalarial drugs. The mosquito breeding sites must be sprayed and removed. So we can prevent human beings from this notorious infection.

Copyright(C) 30 Apr, 2016.

\section{REFERENCES}

1. Park K. Park's text book of preventive and social medicine, Banarsidas Bhanot Publisher, Prem Nagar, Jabalpur,2010;222.

2. Suman Rajeev. Malaria - still unconquered. JAPI2006; 54:843-844.
3. Nayyar GML, Breman JG, Newton PN, Herrington J. "Poorquality anti-malarial drugs in southeast Asia and sub-Saharan Africa". Lancet Infectious Diseases 2012;12 (6): 488-96.

4. Fairhurst RM, Wellems TE (2010). "Chapter 275. Plasmodium species (malaria)". In Mandell GL, Bennett JE, Dolin R (eds). Mandell, Douglas, and Bennett's Principles and Practice of Infectious Diseases 2 (7th Ed.). Philadelphia, Pennsylvania: Churchill Livingstone/Elsevier. pp. 3437-3462.

5. Nadjm B, Behrens RH. "Malaria: An update for physicians". Infectious Disease Clinics of North America 2012;26 (2): 243-59.

6. Bartoloni A, Zammarchi $L$ "Clinical aspects of uncomplicated and severe malaria". Mediterranean Journal of Hematology and Infectious Diseases 2012;4 (1): 2012-026

7. Beare NA, Taylor TE, Harding SP, Lewallen S, Molyneux ME. "Malarial retinopathy: A newly established diagnostic sign in severe malaria". American Journal of Tropical Medicine and Hygiene 2006;75 (5): 790-7.

8. Khadim MT. Malaria a menace at Zhob Garrison. Pak Armed Forces Med J 2002:52; 203-7.

9. Dr.Fariha. Treatment failure of malaria control in Pakistan [Online]. 2008 [cited on June 12, 2009]. Available from URL: http://www. scribd.com/dr hammad/d/21955775-MalariaDr-Fariha.

10. World Health Organization. World malaria Report. Geneva: WHO; 2009.

11. WHO. World Malaria report 2010. [Online]. Available from: www.who.int/malaria/world malaria report_2010/ en/index.html. [Accessed on 2010].

12. A. Mahmood, M.Yasir, Thrombocytopenia: a predictor of malaria among febrile patients of Liberia. Infectious Diseases Journal 2008; 14:41-44.

13. Jadhav U M, Patkar VS, Kadam N N. Thrombocytopenia in malaria-co-relation with type and severity of malaria. JAPI August 2004;(52):615-618

14. Kochar D K ,Das A, Kochar A, Middha S, Acharya S et al. throbocytopenia in plasmodium falciparum, plasmodium vivax and mixed infection malaria- a study from Bikaner. Platelets 2010; 21(8):623-7.

15. Akbar, J. U., Shamsher, A.K. \& Sirajuddin, H. A., 2006. Malaria in children: a study of 160 cases at a private clinic in Mansehra. J. Ayub. Med. Coll., 18: 44-45.

16. Idris, M., Sarwar, J. \& Fareed, J., 2007. Pattern of 
malaria infection diagnosed at Ayub Teaching Hospital Abbottabad. J. Ayub. Med. Coll., 19: 35-36.

17. Durrani, A. B., Durrani, I., Abbas, N. \& Jabeen, M. Epidemiology of cerebral malaria and its mortality. J. Pak. Med. Assoc., 1997; 47: 213-215.

18. Yasinzai, M. I. \& Kakarsulemankhel, J.K. Incidence of malaria infection in rural areas of District Quetta, Pakistan. On Line J. Med. Sci., 2003;3: 766-772.

19. Saleem, I., Pirzada, A.H., Rahman, S. \& Noor-ul-Iman. Cerebral malaria, an experience in NWFP, Pakistan. J. Med. Sci. 2006;14: 35-39.

20. Mabunda S, Aponte J J, Tiago A, Alonso P. A countrywide malaria survey in Mozambique. II. Malaria attributable proportion of fever and establishment of malaria case definition in children across different epidemiological settings. Malaria Journal 2009, 8:74.

21. Jamal, M.M., Jehan, A. \& Nadir, A. Malaria in pediatric age group: a study of $\mathbf{2 0 0}$ cases. Pak. Armed Forces Med. J., 2005;55: 74-77.

22. Mahmood, K. H. Malaria in Karachi and other areas in Sindh. Pak. Armed Forces Med. J., 2005;55: 345-348.

23. Alfonso J, Rodriguez -morales, Sanchez Elia, Vargas Minguel, Piccolo Carmelina. Occurence of thrombocytopenia in plasmodium vivax malaria. Clinical infectious diseases, Oxford journals;41(1):130-131.

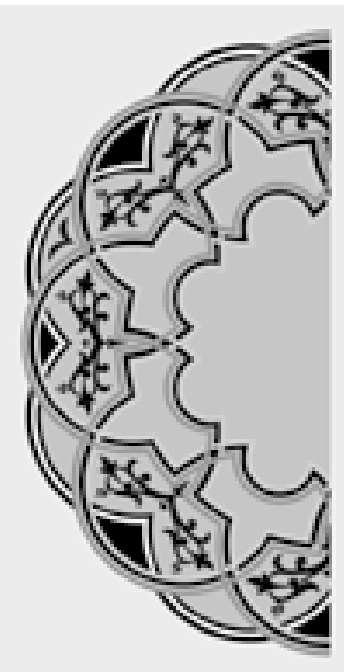

\title{
"Lovely days don't Come to you, You should walk to them."
}

\author{
Rumi
}

\section{AUTHORSHIP AND CONTRIBUTION DECLARATION}

\begin{tabular}{|c|l|l|l|}
\hline Sr. \# & \multicolumn{1}{|c|}{ Author-s Full Name } & \multicolumn{1}{|c|}{ Contribution to the paper } & Author=s Signature \\
\hline 1 & Dr. Muhammad Zafar Majeed & $\begin{array}{l}\text { Clinical Data collection } \\
2\end{array}$ & $\begin{array}{l}\text { Dr. M. Shahbaz Hussain } \\
\text { Lab Data collection ad } \\
\text { analysis, Study design } \\
\text { formatting } \\
\text { Drafting of paper, Lab } \\
\text { Data collection }\end{array}$ \\
\hline 3 & Faiza Sarwar & & \\
\hline
\end{tabular}

